\title{
JOGOS, BRINQUEDOS E BRINCADEIRAS NA INFÂNCIA
}

\author{
GAMES, TOYS AND PLAYS IN CHILDHOOD
}

JOMARA FERREIRA DA SILVA

SABRINA ALVES SANTOS SILVA

Recebido: 21/06/2021 - Aceito: 21/06/2021

\section{RESUMO}

O presente trabalho tem o propósito de expandir os horizontes dos educadores na temática: Jogos, brinquedos e brincadeiras na infância, que será desenvolvido para apresentar não só a necessidade que a criança tem de brincar, mas sim de poder demonstrar como esta brincadeira não é apenas um passa tempo, mas sim uma forma de deixar a criança desenvolver sua inteligência afetiva, o avanço do psico-cognitivo, o seu desenvolvimento físico- motor, o seu relacionamento com o outro, e que trazem consigo experiências derealidades de vida totalmente diferentes, como essa criança deve se portar e principalmente a presença do profissional da educação e da família como mediadores da brincadeira. Neste documento será demonstrado que os pais e professores também devem estar prontos para poder trabalhar com essas crianças, uma vez que com o acesso facilitado aos mais diversos tipos de informações, como os pais e professores deverão trabalhar o conteúdo dessas informações para que possam aguçar a curiosidade na criança deixando-a cadavez mais atenta às regras da brincadeira e ao uso dos jogos e brinquedos. Estetrabalho traz as referências de alguns epistemólogos que não apenas estudaramsobre a brincadeira na educação infantil, mas também deram sua contribuição para que esta pudesse estar presente de forma que ampliasse o conhecimento da criança. Este trabalho traz um questionamento sobre a realidade das criançascom os jogos eletrônicos e as consequências quando a sua dependência, e como a família e a escola devem agir para que as crianças obtenham liberdadecriativa com jogos, brinquedos e brincadeiras e não se tornem reféns ficando atrás de grades e muros que impedem o seu avanço como futuro cidadão do mundo.

Palavras-chave: Lúdico, Educação Infantil, Ensino Aprendizagem

\section{ABSTRACT}

This paper aims to broaden the horizons of educators on the theme: Games, toys and games in childhood, which will be developed to present not only the need for children to play, but also to be able to demonstrate how this game is not. just a 


\section{1/02}

\section{ISSN 2178-6925}

while, but a way to let the child develop his affective intelligence, psychocognitive, his physical-motor development, his relationship with others who bring with them experiences of totally different life realities, such as this child should behave and especially the presence of the education professional and family as mediators of the game. It will be shown in this document that parents and teachers should also be ready to work with these children, as with easy access to the most diverse types of information, how parents and teachers should work on the content so that they can sharpen the curiosity in the child making her increasingly aware of the rules of play and the use of games and toys. This workbrings the references of some epistemologists who not only studied about the play in early childhood education, but also contributed to its presence so that it 
could expand the knowledge of the child and all those involved in early childhood theater. This paper presents questions about the reality of families, electronic games and their evils when addicted and tries to unravel how family and school should act so that children get creative freedom with games, toys and games and do not become hostages behind bars. and walls that hinder its advancement as a future citizen of the world.

Keywords: Ludic - Teaching Learning - Early Childhood Education.

\section{Introdução}

Apresentar um breve estudo sobre JOGOS, BRINQUEDOS E BRINCADEIRAS NA INFÂNCIA, nasceu da necessidade de explicitar o quanto jogos e brincadeiras ajudam no desenvolvimento psico-cognitivo das crianças, ajudando-as a realizar algumas interações sociais e estimular o cérebro a trabalhar de forma mais ágil afim de poder solucionar algumas dificuldades que Ihes serão impostas durante as atividades e claramente fora delas.

Este trabalho tem em um dos seus objetivos criar discussões sobre a importância dos jogos, brinquedos e brincadeiras na sala de aula, mas não de tentar dizer que este é o melhor meio para que o aluno aprenda, e sim de demonstrar como o profissional da educação deve estar atento para que a realização deste trabalho seja feita de forma que leve o aluno ao crescimento tanto físico como mental e com isso fará que não só os envolvidos diretamente ao tema sejam beneficiados, mas também suas famílias e as comunidades onde os alunos estão envolvidos.

Para fundamentar a pesquisa, foram destacados alguns teóricos que relatam o brincar e a sua relação com o amadurecimento cognitivo das crianças; propondo, dessa forma, contribuir de forma eficaz para a educação, enriquecendo a dinâmica das relações sociais em sala de aula, dentro dos muros da escola e no seu entorno afim de que este aluno e os profissionais da educação possam trazer o retorno para a escola de forma que esta possa oferecer cada vez mais meios para o desenvolvimento e formação pessoal e social de outros alunos.

Uma relação natural das crianças com os jogos educativos são que esses alunos não se sentem acomodados com o que é ensinado, mas agindo de forma que lhes é peculiar acabam mudando e criando novas regras, inserindo novos companheiros e fazendo com que a brincadeira sempre tenha outros desafios além dos existentes, fazendo com que seja criado um novo charme, um novo 
método de introdução, desenvolvimento e conclusão cada vez que se inicia o jogo. É na formação dos desafios dos jogos que é verificado e estimulado a personalidade de cada pessoa envolvida. Algumas crianças querem ganhar a qualquer custo e devem ser ensinadas que nem tudo é vitória, algumas querem machucar o adversário para poder fragilizar o oponente e assim vencer de forma mais fácil, ali estes alunos devem ser ensinados que para se obter respeito não basta vencer e sim tem que aprender a respeitar o adversário como ser humano que ele é e não como um inimigo.

Este trabalho terá as explanações de alguns autores como Kishimoto Piaget, Gadotti e Brenelli e outros e suas visões acerca do tema Jogos, brinquedos e brincadeiras na infância, a função da família e da escola no desenvolvimento que impulsionará o crescimento de todos os envolvidos.

Existem muitas formas de se trabalhar os jogos e brincadeiras, sejam com materiais de primeira linha ou com materiais simples, os jogos tem a função de elevar o nível cognitivo de cada aluno e assim o profissional da educação poderá trabalhar os conteúdos linguagem, oralidade, músicas populares, teatro, jogos e brincadeiras.

\subsection{Objetivos}

Mostrar a importância dos JOGOS, BRINQUEDOS E BRINCADEIRAS NA INFÂNCIA e sua importância no ambiente escolar, além de tratar sobre o conhecimento dos profissional da Educação Infantil e sua prática de forma lúdica em sala de aula.

* Criar discussões sobre a importância dos jogos, brinquedos e brincadeiras na sala de aula.

* Relacionar jogos e brinquedos e brincadeiras ao processo de ensinoaprendizagem.

* Analisar o jogos e brinquedos e brincadeiras no contexto social.

* Investigar jogos e brinquedos e brincadeiras no ambiente familiar.

* Identificar os tipos de jogos e brinquedos e brincadeiras.

\section{Revisão da Literatura}

O tema Jogos, brinquedos e brincadeiras, foi escolhido com o intuito de agregar um maior conhecimento sobre esta área que está cada vez mais sendo utilizada nos meios escolares. As atividades lúdicas atraem a atenção das crianças, auxiliam de forma positiva na socialização do aluno e contribuem para 
que a criança desenvolva o seu lado psico-cognitivo através da atenção e do trabalho sozinho ou em grupo.

As alunas que participam do processo de construção desse artigo, ao analisar, catalogar e resumir os assuntos relacionados ao tema escolhido, perceberam que se trata de uma questão com várias facetas e conta com inúmeras formas de se trabalhar, o que favorece o campo de atuação e pesquisa.

Os jogos têm uma relação estreita com os brinquedos e também com a história e a cultura, uma vez que cada povo procura instruir seus filhos de acordo com o que rege o momento atual da sociedade.

Desde sempre a sociedade não consegue aceitar abertamente aquelas pessoas que não conseguem ser boas em alguma coisa, ou até mesmo os próprios pais começam a refutar seus filhos por conta de alguns fracassos quando na verdade é uma simples falta de aptidão para aquilo que os pais um dia imaginaram ser aquela criança.

\subsection{Jogos e brincadeiras ao longo da história}

Os jogos são de extrema importância na didática escolar e no tempo familiar que a criança passa fora dos muros escolares. Mas como é a história dos brinquedos? Na verdade os brinquedos e brincadeiras surgem de diversas formas, umas por pura inocência e outras por algumas concepções de sua época.

Como estamos no país do futebol não poderíamos deixar de fora a bola, este brinquedo que fascina milhões de pessoas pelo mundo e que tornou o nosso país o maior campeão de todas as Copas do Mundo. A bola teve um dos seus primeiros registros no Japão quando eram feitas com fibra de bambu, já em Roma e na Grécia usavam tiras de couro e usavam penas e algumas partes de animais para que a bola ficasse recheada. E a boneca? Essa era usada no Egito antigo, cerca de 3 mil anos antes de Cristo e segundo historiadores, elas já foram encontradas em túmulos onde haviam crianças, as bonecas eram feitas de madeira e banhadas com argila, os cabelos eram de verdade, e estas bonecas eram depositadas nos túmulos para que as crianças pudessem brincar no além mundo. Em Roma, quando era chegada a hora do casamento, as mulheres 


\section{1/02}

ISSN 2178-6925

deveriam entregar as suas bonecas, este era o sinal que ali acabava o período infantil e se chegava a vida adulta.

Os brinquedos têm os seus significados, ajudam na interação social e conduzem as crianças para um desenvolvimento não apenas físico, mas também mental, logo baseado neste pensamento que nota-se o porquê cada povo em sua determinada época induziam as crianças a tais brinquedo e brincadeiras. No âmbito escolar surgiu o quebra-cabeças, que foi inventado em 1763 pelo inglês John Spilsbury com o intuito de ajudar os professores a lecionarsobre a matéria de Geografia, proporcionando assim o momento lúdico entre o professor e seus alunos, aumentando a interação e facilitando o aprendizado.

Froebel também teve a sua contribuição quando estabeleceu através de atividades lúdicas o uso do brinquedo como forma de fazer com que a criança pudesse se expressar de maneira criativa e também fazendo uso de vários materiais como papel, argila e serragem. (ABRÃO, 2012).

Estes três brinquedos são exemplos da construção da identidade de uma sociedade e mostra como cada um tem a sua história e sua importância durante os períodos que foram criados e em sua grande maioria eles exercem uma forte influência até os períodos de hoje.

\subsection{O papel do educador nos jogos e brincadeiras}

O educador tem um papel importante na atividade de brincadeira com seus alunos, é durante este período que o profissional da educação utiliza de brinquedos e jogos para poder buscar no aluno uma interação maior entre eles, cria um laço de afetividade e ajuda os alunos a manter uma relação social que pode levá-los a conflitos pessoais e em grupo, assim o educador poderá agir como interventor e ajudar as crianças a superarem suas dificuldades.

O professor deve se preparar antes de utilizar jogos e brincadeiras, ele deve ter em mente os diferentes tipos de alunos que estão naquela escola, qual a realidade deles e qual a mudança que aqueles jogos causarão na vida dos alunos. A organização do espaço lúdico é importante, pois um ambiente bem preparado e propício para a atuação de todos os integrantes da brincadeira, e auxilia o trabalho do professor no desenvolvimento do jogo. 
A participação do professor nos jogos e brincadeiras deve ser feita de forma sistematizada para que haja um equilíbrio entre a atividade lúdica e o aprender através do uso dos brinquedos. Os brinquedos são fonte inesgotáveis de interação social, lúdica e afetiva entre professor e alunos e entre os próprios alunos. Cada jeito de brincar exige regras que já vem impostas, mas que no decorrer da brincadeira podem ser mudadas, dando assim mais emoção, impondo dificuldades e causando diversas experiências emocionais e cognitivas na vida dos alunos. Quando esta vontade é interligada com a aprendizagem, o estudo se torna prazeroso e é realizado de forma intensa e abrangente. (MALAQUIAS, 2013).

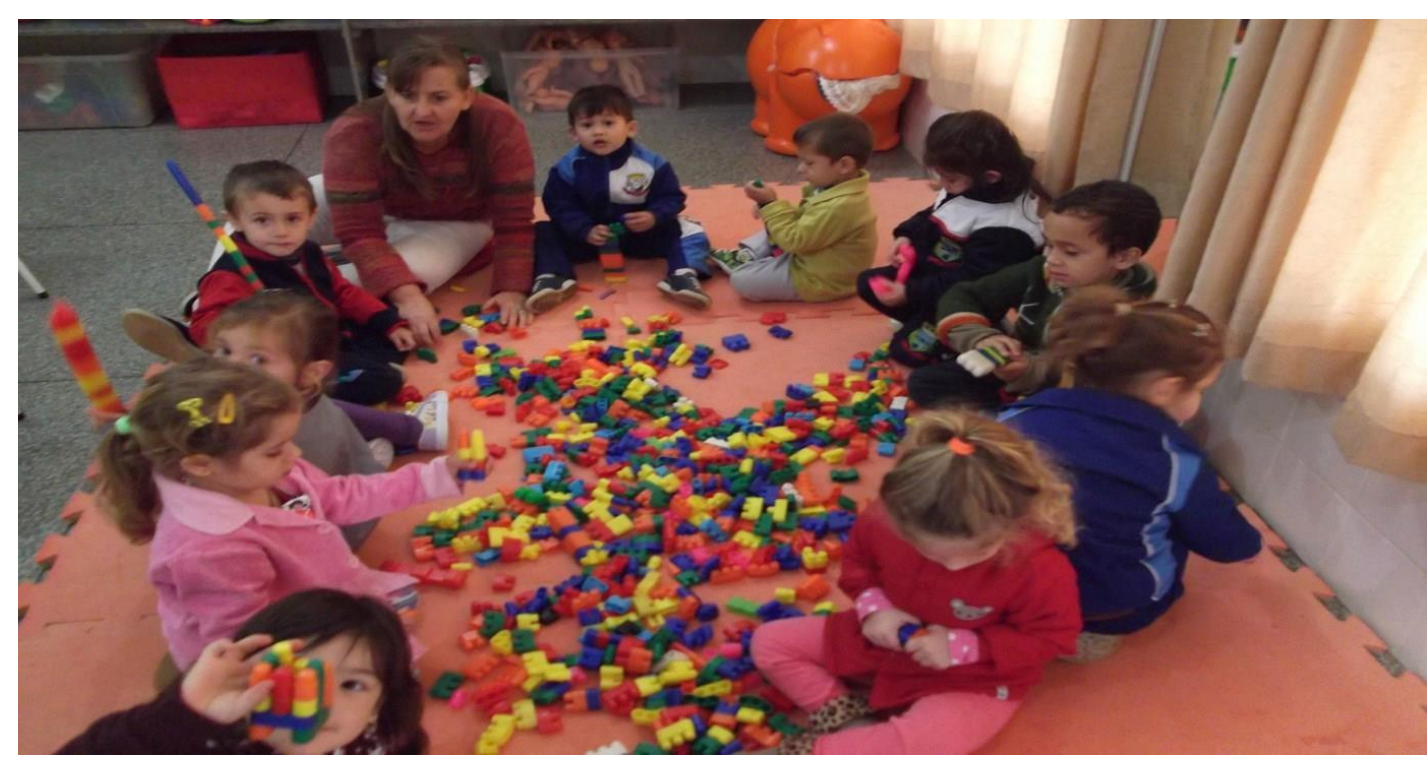

Para alcançar os objetivos pedagógicos, e realizar o desenvolvimento da criança através dos jogos, brinquedos e brincadeiras fazendo com que funcione como uma engrenagem perfeita, é necessário que o educador tenha em seu currículo a capacitação lúdica, busque também trocar informações sobre as atividades lúdicas com professores mais experientes, participe de fóruns e quando da sua atuação frente aos alunos na realização da atividade de brincar, não queira que aquele momento seja apenas uma forma de passar o tempo, gastar o horário, mas o utilize buscando adequar a brincadeira com o planejamento pedagógico feito pela escola e pelo preparo da sua aula, seja ela semanal ou mensal.

A descoberta do universo infantil é algo fundamental na carreira do profissional educador, a atualização do professor frente aos jogos eletrônicos e o acesso fácil que as crianças têm a esses equipamentos tornam as brincadeiras 


\section{1/02}

ISSN 2178-6925

com materiais físicos cada vez mais importantes. A criação de histórias sendo iniciada pelo professor, utilizando os recursos expostos na sala de aula ou em algum espaço onde este evento pode acontecer, leva o aluno a imaginar a continuação da história, e com isso o professor pode incentivar o gosto pela leitura de revistinhas e gibis voltados para a idade que contempla os seus alunos.

É preciso que após a iniciativa de desenvolver a história, o professor proporcione aos alunos uma maneira dele ser crítico e ter autonomia para dar continuidade aos trabalhos que cercam o que foi dado. Buscar uma forma de manter os alunos interessados, trazer a atenção deles, não deixar que nenhum aluno se afaste do grupo ou se esconda da brincadeira, por isso se faz necessário que o professor seja bem capacitado para que no fim a atividade seja prazerosa.

Ao ter esta consciência da importância da brincadeira que citamos o que diz ANCILENO E CALDEIRA (2007):

Para a criança, as brincadeiras proporcionam um estado de prazer, o que leva à descontração e, consequentemente, ao surgimento de novas ideias criativas que facilitam a aprendizagem de novos conteúdos e interações conscientes e inconscientes, favorecendo a confiança em si e no grupo em que está inserida. (ANCILENO; CALDEIRA 2007, p. 03).

Após cada brincadeira, cada utilização de brinquedos, é importante que o professor faça uma avaliação de cada criança, para que este possa corrigir alguns comportamentos e também extrair o melhor do potencial que o aluno tem para os estudos.

\subsection{Aprendizagem em meio a brinquedos e brincadeiras}

Existe uma prática de ensino baseada nos jogos e brincadeiras que está inserida em nossa cultura e que cada vez mais ela tende a evoluir. Esta prática é que ao invés de se trabalhar o individual, se faz evoluir o indivíduo, cada pessoa é única e com isso merece também uma atenção única voltada para suas necessidades e anseios frente a nova realidade que enfrenta durante o período escolar.

Esta prática auxilia no desenvolvimento não só cognitivo, mas também o emocional, levando as crianças a confrontarem problemas que poderiam levá- 
las a perderem o estímulo pelos estudos ou de enfrentar alguns desafios que possam surgir.

Segundo o biólogo e um dos maiores influenciadores da metade do século $X X$, Jean Piaget, o ser humano é ativo na construção de seu conhecimento e não uma massa disforme a ser moldada pelo professor. Por isso o educador deve estar sempre atento aos movimentos das crianças durante as participaçõesem jogos e brincadeiras na escola.

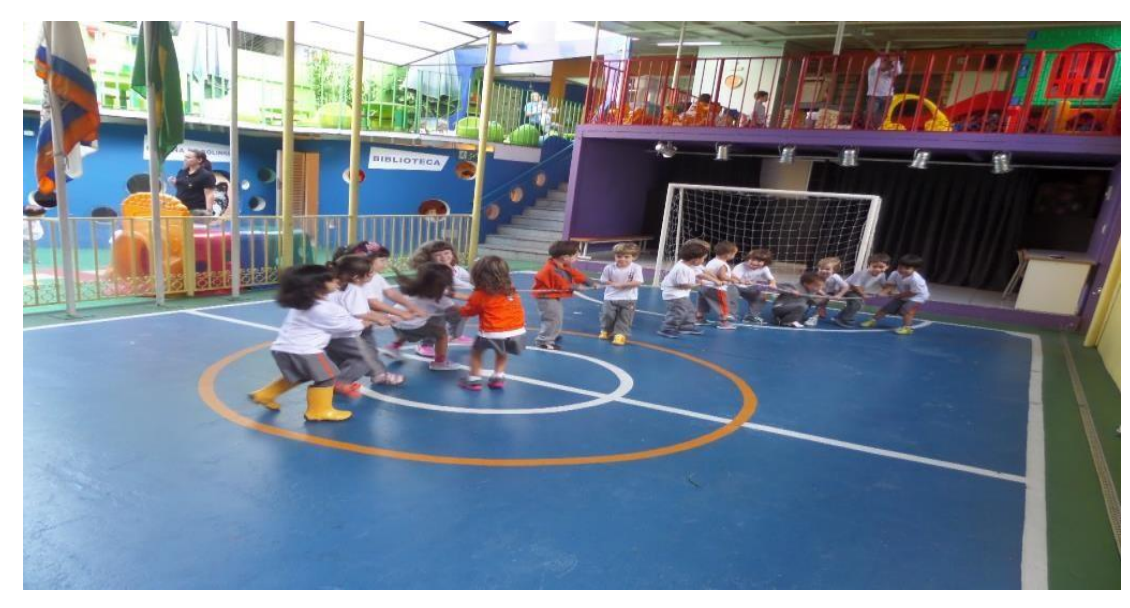

A função dos jogos, brinquedos e brincadeiras é fazer com que o aluno aprenda enquanto brinque, mas para que essa aprendizagem aconteça é necessário que o professor faça as brincadeiras fluírem de maneira que traga e prenda a atenção dos alunos para que não se dispersem ou cansem de brincar. Faz-se necessário que o aluno entenda qual o sentido da brincadeira quando ela é direcionada, mas também que ela possa ter autonomia e direcionar a sua própria brincadeira.

Antigamente se tinham os jogos como forma apenas de brincadeiras, mas para algumas sociedades como a romana e a grega, também serviam de parâmetro para treinamento de crianças, fossem meninos ou meninas para que essas exercessem sua função na sociedade. Os jogos, as brincadeiras e festas sazonais tradicionais também serviam para estreitar os vínculos afetivos e sociais com as crianças (ARIÈS, 1978). Como neste período contemporâneo temos um estudo cada vez mais aprofundado para medir entre o brincar sem direcionamento como forma de diversão natural das crianças e o brincar com direcionamento como forma pedagógica de se trabalhar, e incentivar o trabalho 
em conjunto para que assim haja uma interação positiva no desenvolvimento das brincadeiras como formas de evolução humana.

\subsection{O lúdico na educação infantil}

Ao estudar a BNCC (Base Nacional Comum Curricular), observa-se nela que dentro das seis leis em relação a educação infantil há o direito de brincar inserido em seu campo que assim são definidos: conviver, brincar, participar, explorar, expressar e conhecer-se. $\mathrm{O}$ jogo, os brinquedos e as brincadeiras são partes de um processo que atendem o aprendizado e o desenvolvimento da criança.

$\mathrm{Na}$ atual conjuntura que se encontram as escolas nacionais, quase todas inseridas no modelo de Escola Democrática, estas praticam o tipo de aprendizado onde as crianças são as protagonistas das brincadeiras, elas induzem as crianças a elevarem seu nível de entendimento dos jogos e auxiliam o desenvolver do pensamento de raciocínio lógico. Durante estes trabalhos de indução, as famílias e as comunidades são convidadas a participarem, fazendo com que todos possam participar do processo de construção e decisão da comunidade escolar.

Nos tempos modernos onde cada vez os pais e/ou responsáveis preferem entregar o celular a seus filhos que participar ativamente do dia a dia da criança, como fazer tudo isso voltar a funcionar? A resposta ainda está sendo estudada, afinal não basta apenas desligar o celular, hoje a tecnologia é altamente presente em todos os campos da sociedade, mas como nem todas as escolas dispõem de materiais de qualidade e nem de recursos tecnológicos suficientes para atender a demanda educacional, estes fatores transformam o educar através de jogos, brinquedos e brincadeiras, algo cada vez mais difícil de se trabalhar. 


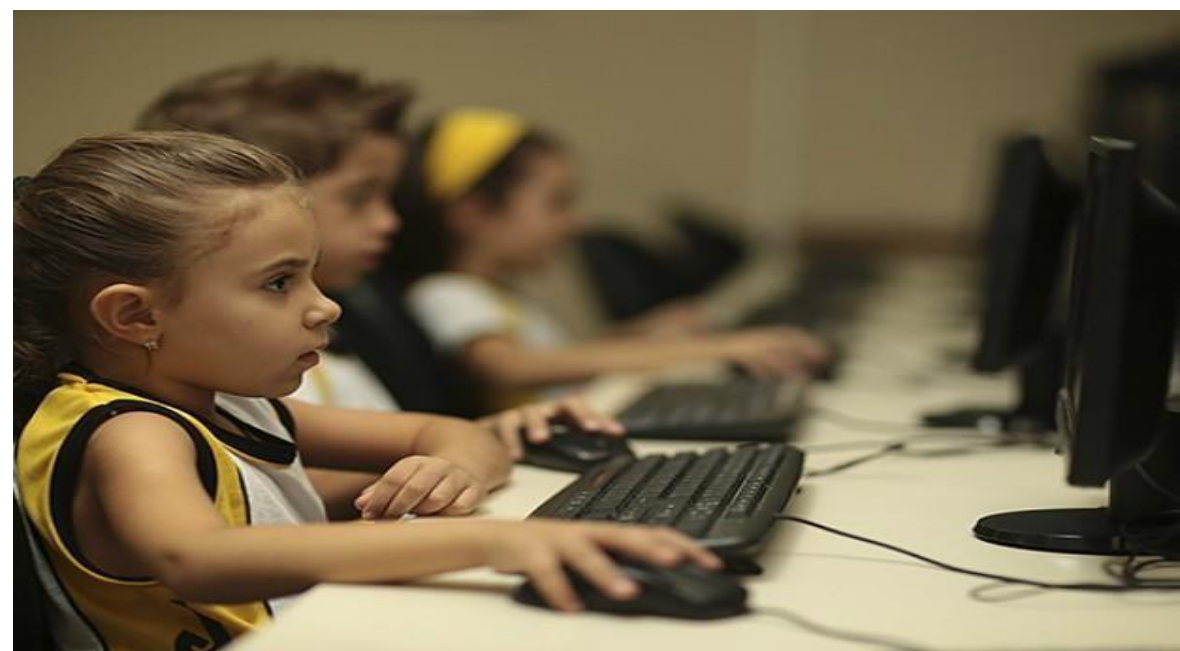

As crianças têm o seu tempo de aprender os assuntos pedagógicos da escola, e cabe ao professor inovar com jogos e brincadeiras para que aqueles alunos com maiores dificuldades possam se encaixar no andamento do grupo e todos possam caminhar de maneira igualitária, sem deixar ninguém para trás. Por mais que a escola se esforce para que o lúdico seja bem aceito, bem entendido pelo aluno, se a família e a comunidade não participarem, raramente o professor obterá o sucesso desejado.

O trabalho lúdico não deve ser feito para que pais e professores classifiquem as crianças pelas notas, pela excelência no desenvolvimento pedagógico, mas sim deve buscar uma forma de buscar extrair o melhor dos seus talentos e fazer estes talentos se desenvolverem para criar no aluno uma resposta positiva frente aos trabalhos educacionais e sociais.



\subsection{As atividades lúdicas e o desenvolvimento infantil}

Aspecto cognitivo, psicológico e psicomotor

Segundo Piaget, as fases do desenvolvimento infantil são: 
- Inteligência sensório-motora: de 0 a 2 anos;

- Pré-operatória: de 2 a 7 anos;

- Operatório concreto: de 7 a 12 anos;

- Operatório formal: a partir dos 12 anos.

Para Piaget, estas fases precisam estar completamente construídas para que a criança possa passar para a próxima fase, logo estas fases se tornam inflexíveis dentro da escala evolutiva.

Os brinquedos têm a sua importância na fase evolutiva da criança, com o passar dos tempos, cada uma vai se interessado por um brinquedo maior, mais evoluído e que atenda às suas necessidades atuais. Mas para que isso ocorra, as crianças devem ser estimuladas a querer estar num outro patamar, abandonando o conceito antigo de infância e automaticamente partindo para o próximo. Este trabalho levará a criança a desenvolver-se cognitivamente e desempenhar as mais diversas funções dentro do campo que a sua idade corresponde.

É de suma importância que os brinquedos e brincadeiras levem ao estímulo físico a criança portadora deste. O brinquedo que apresenta diferentes funções, sejam elas eletrônicas ou de movimentação de suas partes de forma mecânica e simples, fazem com que a criança se sinta estimulada a criar gestos corporais, fazendo com que haja um trabalho natural do seu corpo em relação ao brinquedo.

A partir da utilização de brinquedos que a criança consegue aguçar seus pensamentos, marcar os sons emitidos por cada um destes brinquedos, realizar e memorizar cada parte dele e como funciona, assim a criança aprende intuitivamente a sobre o funcionamento de cada brinquedo que ela utiliza.

Os brinquedos não só auxiliam as crianças no trabalho psicomotor, elas também realizam uma função importantíssima que é a psicológica, pois é através destes brinquedos e jogos que as crianças iniciarão contatos com outras crianças, produzindo assim sua primeira interação social, experimentando novos desafios como a troca de brinquedos e o de emprestar aquilo que sempre foi de sua propriedade. Exercer estas habilidades sociais devem ter 0 acompanhamento dos adultos, mas é aconselhável que deixe as crianças 
tomarem atitudes sozinhas, evitando que possam se retrair frente a uma ordem que ele não gostaria de ter obedecido. Forçar a criança não é a melhor forma de iniciar uma interação social entre ela e outras crianças, pois pode afetar negativamente o psicológico levando a criança a ter raiva e se negar futuramente a aprender a dividir.

\subsection{Classificação dos jogos}

Simbólicos, regras, educativos, exercício sensório motor.

Quando o simbolismo é ultilizado na classificação dos jogos, percebe-se que as crianças ao participarem de uma brincadeira, cada uma tem o seu objetivo e geralmente este objetivo não é alterado. Vigotsky entende o simbolismo da seguinte maneira: "A situação imaginária de qualquer forma de brinquedo já contém regras de comportamento" (Vigotsky 1988 p. 124). Um exemplo disso é quando a criança está no carro da família e acaba por imitar umdos motoristas, suas atitudes, seus jeitos, suas falas e suas cobranças em relação ao cinto de segurança de todos os passageiros.

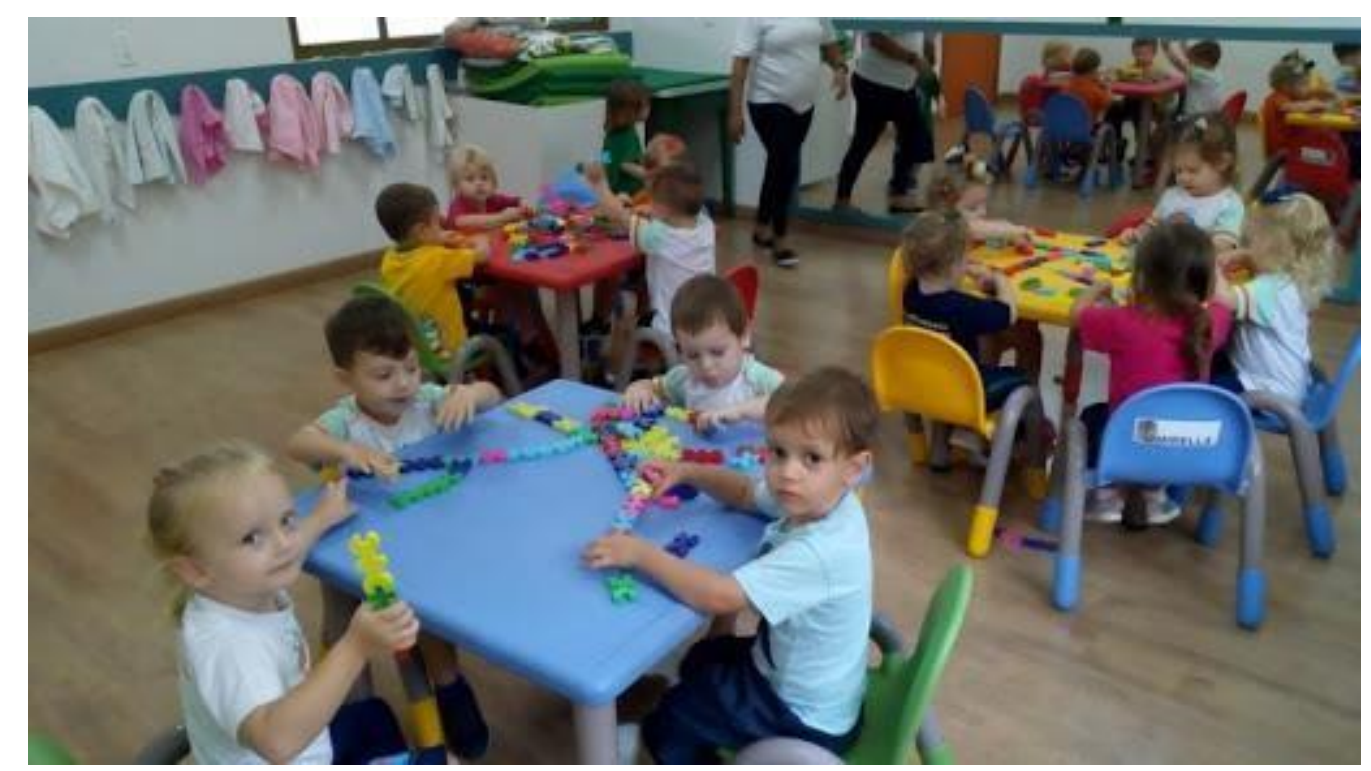

Outro exemplo é quando se constrói com alguns tijolos e se imagina num castelo, onde ele é o rei, dá as ordens e cria regras para outras crianças, ou talvez o príncipe que resgatará a princesa, comandando os seus subordinados afins que hajam conforme os seus comandos durante um ataque a um reino ou outro castelo, neste momento ele entra para o seu mundo imaginário e sai do 
cenário baseado na realidade, passando a ser um criador de histórias e não apenas um copiador delas.

Os jogos educativos ajudam as crianças a evoluir o pensamento, mas não são todas as crianças que conseguem deixar explícito o que realmente aquele jogo quer dizer, aquela brincadeira quer mostrar. Em algumas fases eles nem conseguem explicar o porquê das coisas, mas mostram que apenas estão brincando por brincar, apenas para se divertirem.

Segundo Teles (1999) a brincadeira, o jogo e o humor colocam o indivíduo em estado criativo. Mas para que essa situação aconteça, é necessário que a criança esteja num ambiente onde ela possa expressar seus desejos, tenha liberdade de pensamento e possa agir dentro do que tenha imaginado para sua atividade de brincar.

O brinquedo não só possibilita o desenvolvimento de processos psíquicos, por parte da criança, como também serve como instrumento para conhecer o mundo físico (e seus usos sociais), e, finalmente, entender os diferentes modos de comportamento humano (os papéis que desempenham, como se relacionam e os hábitos culturais...) Para que as brincadeiras infantis tenham um lugar garantido no cotidiano das instituições educativas é fundamental a atuação do educador. É importante que as crianças tenham espaço para brincar, assim como opções de mexer no mobiliário, que possam, por exemplo, montar casinhas, cabanas, tendas de circo, etc. O tempo que as crianças têm à disposição para brincar também deve ser considerado: é importante dar tempo suficiente para que as brincadeiras surjam, se desenvolvam e se encerrem. (REGO citado por TELES, 1999, p.16).

Ainda segundo Teles (1999), a família e os profissionais da educação devem dar apoio para que as crianças possam desenvolver suas criatividades com o máximo de prazer e imaginação, de modo que esta criança se sinta segura, criativa, equilibrada e tenha sua autoestima elevada.

A criança aprende através de jogos a ter uma melhor coordenação dos seus do seu corpo, fazer com que funcione o seu lado sensório-motor com maior eficácia. Os adultos são os facilitadores, os intermediadores dos jogos, através destes adultos que as crianças sentirão estímulos para dar continuidade as suas atividades. Estes jogos que tenham a interação dos pais, são mais suscetíveis para a criança mostrar que aprendeu e queira ensinar seus colegas como fazer, assim acabam por copiar o jeito dos pais. 


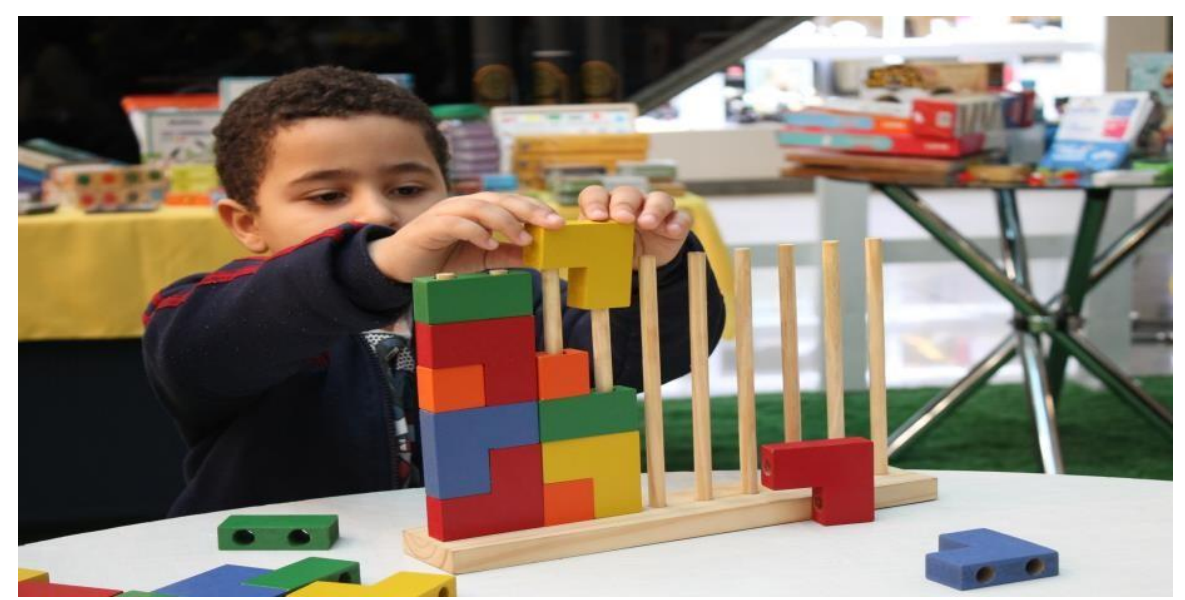

\subsection{Espaço Lúdico}

As atividades lúdicas são essenciais para o processo de desenvolvimento do aluno, é através delas que ele amplia o seu processo de aprendizagem e de socialização através do contato e participação de outras crianças e adultos na brincadeira.

Atualmente tem-se nas escolas um espaço construído para a recepção e desenvolvimento de jogos e brincadeiras, esse espaço é conhecido como brinquedoteca e é de fundamental importância, pois é neste lugar que acontecem os direcionamentos da brincadeira de modo a facilitar a interação dos alunos e também de ajudar os alunos a entenderem o plano pedagógico do professor.

Ao tratarmos da brinquedoteca e suas funções deparamos com uma frase de Jean Piaget, "a atividade lúdica é o berço obrigatório das atividades intelectuais da criança, sendo por isso, indispensáveis a prática educativa". Segundo Nylse Helena Silva Cunha, "A brinquedoteca não existe para distrair as crianças, ela reporta-se a formação do ser humano integral e aos vários períodos que ela atravessa.

Partindo destas declarações nota-se que não basta apenas o profissional da educação ir com a criança até o pátio da escola e os deixar lá para brincarem como quiserem, sem regras, sem objetivos e sem acompanhamento. O professor deve acompanhar todas as atividades, visualizar como cada aluno se comporta e como eles exercem as regras básicas de convivência como por exemplo o respeito. A brinquedoteca tem a função de oferecer materiais, brinquedos e jogos para as crianças que possam contribuir com a capacidade de concentração, 
ampliar a imaginação e como os alunos se organizarão para a construção da brincadeira.

O professor como mediador deve estar atento para conhecer os futuros líderes que ali se encontram, como são as reações de perda ou de ganho no jogo, como seus sentimentos afetivos trabalham e também como estas crianças podem expressar-se diante das situações impostas pelos jogos.

Dentro de uma brinquedoteca, a criança tem inúmeras chances de melhorar "os sentidos, exercitar os músculos, coordenar a visão com o movimento, obter domínio sobre seus corpos, tomar decisões e adquirir novas habilidades", Papalia e Feldman (2013, pág. 296). Diante de tais argumentos, o professor e/ou a família não podem entender que as crianças brincam apenas por brincar, elas de uma maneira intuitiva estão adquirindo habilidades que Ihes servirão de norte para uma vida, a criatividade, o desenvolvimento físico e emocional, o aprendizado pedagógico e social ajudará esta criança a ter alicerces cada vez mais firmes para sua construção de identidade.

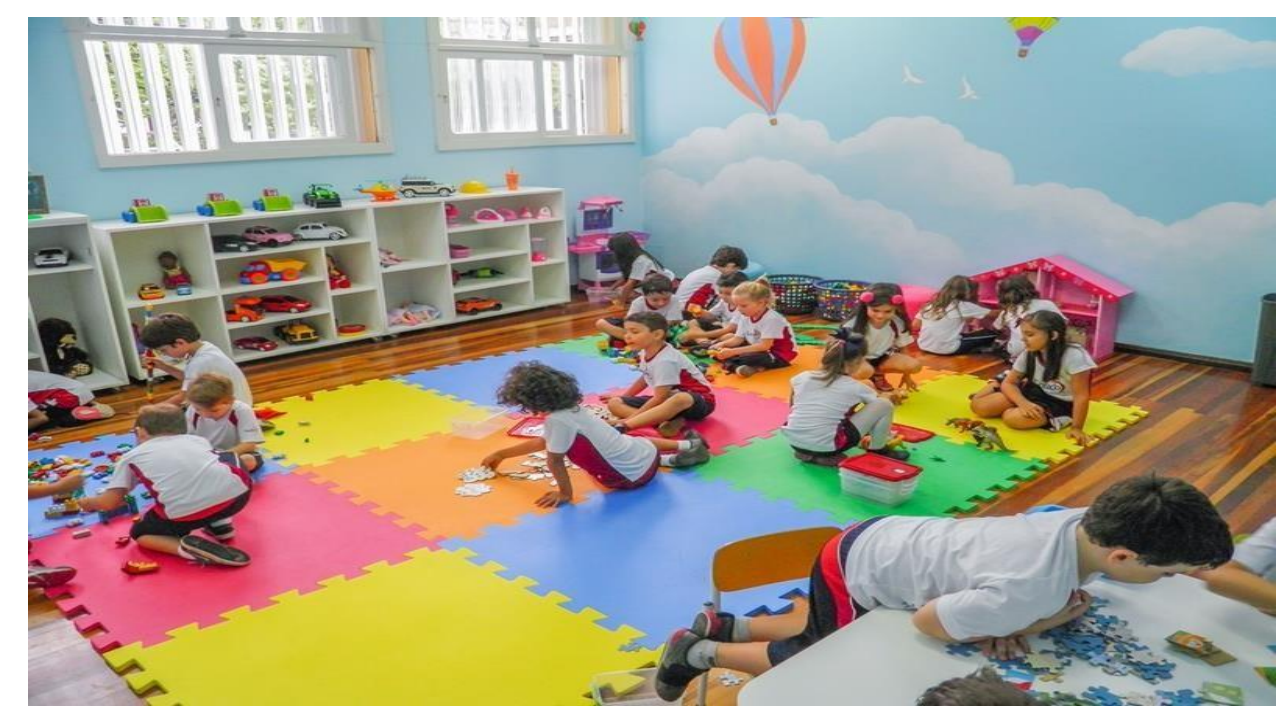

Essa questão do brincar, de interagir, de evoluir a criança socialmente e psicologicamente estão contidas na Constituição Federal - CF (1988) em seu artigo 227 e no Estatuto da Criança e do Adolescente - ECA (1990) em seus artigos 4 e 16. Sabendo da realidade das escolas percebemos que nem todas dispõem de salas preparadas para receber os alunos, e que quando algumas conseguem o espaço, os brinquedos na sua grande maioria são resultados de doações da própria comunidade e de alguns empresários. Nos locais de maior 


\section{1/02}

ISSN 2178-6925

dificuldade ao acesso para lazer, que também sofrem com o desemprego e falta de mobilidade urbana, dificultam para a criança poder vivenciar, poder curtir este momento de sua infância. Algumas começam a trabalhar muito cedo para ajudar o pai e a mãe nas despesas ou para apenas poder colocar um pouco de comida a mesa. Esse tipo de exposição é nocivo ao desenvolvimento social e particular daquela criança, pois não permitem a vivência e a convivência com outras crianças e não exercem de modo pedagógico a brincadeira.

A profissão de ser professor vai além de simplesmente entrar em sala de aula e despejar nos alunos as matérias no quadro, o professor deve estar preparado para criar e acompanhar o momento de prazer das crianças, para que possa identificar aquelas crianças que mesmo pequenas já são referência de liderança para os outros, o professor deve proporcionar e direcionar uma maior interação, socialização e principalmente proporcionar a alegria, pois é para essa finalidade que que existe o espaço lúdico com seus jogos, brinquedos e brincadeiras, é o aprender em forma de diversão.

\section{Considerações Finais}

Como visto no decorrer deste trabalho, foi possível entender o que são os jogos, brinquedos e brincadeiras, suas singularidades que acabam tendo 0 mesmo objetivo, o de tornar as crianças cada vez cidadãos mais felizes, inteligentes, conscientes da sua realidade e capazes de se modificarem e modificarem o lugar onde vivem.

A educação infantil é a base para a evolução da criança, não somente seu lado pedagógico, onde o aluno senta numa cadeira e recebe informações, mas como essas informações são transmitidas, de que modo o professor preparou sua aula para que pudesse prender a atenção do aluno e criar nele um desejo de se modificar e modificar tudo ao seu redor para melhor.

Foi possível verificar que os jogos, brinquedos e brincadeiras são partes obrigatórias na vida de uma criança, ela tem que estar presentes e devem ser facilitadas pelos pais e professores para que mesmo com dificuldades de recursos materiais, financeiros ou do costume, a criança possa vivenciar o seu período de vida. 
Foi citado um número bastante considerável de estudiosos e colaboradores que não apenas escreveram sobre o brincar na infância, mas também demonstraram como e porque as crianças deve ter o seu tempo para brincar. É claro que não por sua importância as crianças devem passar do amanhecer ao anoitecer brincando, não é essa a motivação deste documento, mas que as crianças não sejam privadas de fazer aquilo que é da sua idade, vivenciar e experimentar brincadeiras individuais e coletivas.

Não há uma definição para o ato de brincar, mas há o objetivo inserido na brincadeira, nos jogos e nas atividades com os brinquedos, cada uma em sua particularidade demonstra que é possível explorar a criatividade, a imaginação e o prazer da descoberta pessoal e grupal.

$\mathrm{O}$ ato de brincar eleva a autoestima da criança, e abre campo para o processo de construção mental, ampliando o seu alcance pessoal e social de forma a atingir satisfatoriamente o respeito as regras de convivência social e familiares. Com isso a criança passa a ganhar experiência para que suas opiniões e desejos possam ser recebidos e entendidos com maior clareza por aqueles que os rodeiam.

O espaço escolar deve ser bem definido para que todos os trabalhos possam ser desenvolvidos e os resultados sejam alcançados de maneira concreta. Observar como cada criança reage diante das dificuldades e fazê-las crer que é possível reverter, recriar e superar as dificuldades, só fortalecem a mente e o corpo, criando nesta criança uma pessoa cada vez mais capaz de fazer deste um mundo melhor para se viver.

A escola deve proporcionar aos seus alunos ambientes favoráveis à criação, à imaginação e à inventividade para que possam desenvolver o brincar de maneira livre e consciente, junto deste momento o professor deve ser sempre seu incentivador e apoiador tanto nos momentos de vitória como nas decepções.

\section{Referências}

ABRÃO, K. A política de organização da infâncias e o currículo da Educação Infantil e do primeiro ano. Zero-a-seis, v.1. Florianópolis: UFSC,2012. 
ALMEIDA, Paulo Nunes de. Educação Lúdica - técnicas e jogos pedagógicos. São Paulo: Edições Loyola, 1987.

ANCINELO, P. R.; Caldeira, L.P. O papel dos jogos lúdicos na educação contemporânea. São Paulo, 2007.

ARIÉS, P. (1978) História Social da Criança e da Família. Rio de Janeiro: Zabar Editores.

Base Nacional Comum Curricular (BNCC). Educação é a Base. Brasília, MEC/CONSED/UNDIME, 2017.

BRASIL. Estatuto da Criança e do Adolescente. Lei no 8069 de 13 de julh de 1990.

BRASIL, Ministério da Educação. Secretaria de Educação Média e Tecnologia. RCN - REFERÊNCIAS CURRICULARES NACIONAIS - Educação Infantil. Brasília: Ministério da Educação, 1999. . Referencial Curricular para a Educação Infantil, RCNEI. 1998.

CUNHA, Nylse Helena Silva.Brinquedoteca: um mergulho no brincar. São Paulo: Maltese,1994.

MALAQUIAS, Maiane Santos; RIBEIRO, Suely de Souza. A importância do lúdico no processo de ensino aprendizagem no desenvolvimento da infância. Psicologado, 2013. Disponível em: <htt://psicologado.com/atuacao/psicologiaescolar/a-importancia-do-ludico-no-processo-de-ensino-aprendizagem-nodesenvolvimento-da-infancia

MINAYO, M. C. S. (Org.). Pesquisa Social: Teoria, Método e Criatividade. Petrópolis: Vozes, 1995.

PAPALIA, D. E. e FELDMAN, R. D. (2013). Desenvolvimento Humano. Porto Alegre, Artmed, $12^{\mathrm{a}}$ ed.

PIAGET, J. A formação do símbolo: imitação, jogo e sonho, imagem e representação. 3. ed. Rio de Janeiro: Zahar, 1975.

VIGOTSKY, Lev Semenovich. Aprendizagem e desenvolvimento intelectual na idade escolar. In: VIGOTSKY, Lev Semenovich; LURIA, Alexander Romanovich, LEONTIEV, Alexis N. Linguagem, desenvolvimento e aprendizagem. Tradução de Maria da Penha Villalobos. 2 ed. São Paulo: Ícone, 1988. p.124 
Faculdade Presidente Antônio Carlos de Teófilo Otoni

FICHA DE ACOMPANHAMENTO INDIVIDUAL DE ORIENTAÇÃO DE TCC

Atividade: Trabalho de Conclusão de Curso - Artigo/Monografia.

Curso: PEDAGOCIA Período: $7^{\circ} / 8^{\circ}$ Semestre: $2^{\circ}$ Ano: 2020

Professor (a): GEOVANA MARIA DOS SANTOS GOMES

Acadêmico: JOMARA FERREIRA DA SILVA

Tema: Jogos, Brinquedos E Brincadeiras na Educação Infantil

\begin{tabular}{|c|c|c|}
\hline Data(s) do(s) atendimento(s) & HORARIO & Assinatura do aluno \\
\hline $10 / 07 / 2020$ & $19 \mathrm{H}$ às $19 \mathrm{~h}: 30 \mathrm{mim}$ &  \\
\hline $14 / 08 / 2020$ & $19 \mathrm{H}$ às $19 \mathrm{~h}: 30 \mathrm{mim}$ & \\
\hline $28 / 08 / 2020$ & $19 \mathrm{H}$ às $19 \mathrm{~h}: 30 \mathrm{mim}$ & \\
\hline 09/09/2020 & $19 \mathrm{H}$ às $19 \mathrm{~h}: 30 \mathrm{mim}$ & iom \\
\hline $18 / 09 / 2020$ & $19 \mathrm{H}$ às $19 \mathrm{~h}: 30 \mathrm{mim}$ & romula \\
\hline 09/10/2020 & $19 \mathrm{H}$ às $19 \mathrm{~h}: 30 \mathrm{mim}$ & vina dx \\
\hline $23 / 10 / 2020$ & $19 \mathrm{H}$ às $19 \mathrm{~h}: 30 \mathrm{mim}$ & Loman \\
\hline $06 / 11 / 2020$ & $19 \mathrm{H}$ às $19 \mathrm{~h}: 30 \mathrm{mim}$ & 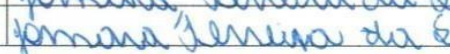 \\
\hline
\end{tabular}

Descrição das orientações:

Considerando a concordância com o trabalho realizado sob minha orientação, AUTORIZO O DEPÓsıTo do Trabalho de Conclusão de Curso do (a) Acadêmico

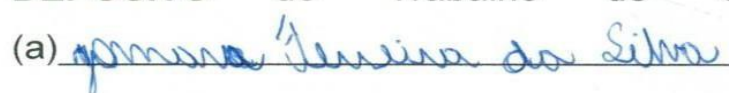

Assinatura do Professor 
Revista Multidisciplinar do Nordeste Mineiro, v.2 2021/02

ISSN 2178-6925

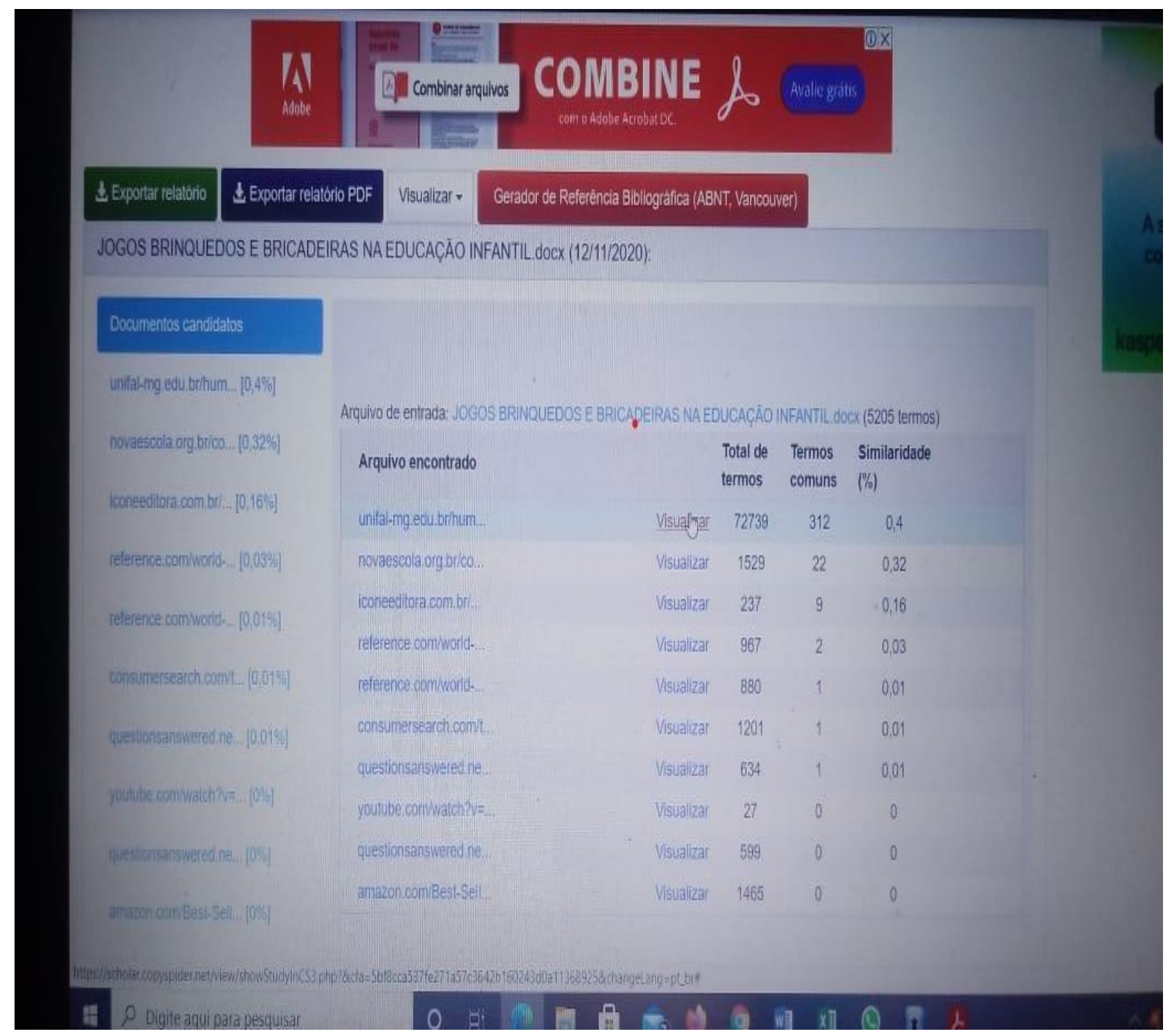

